\title{
The Design of Wind Pendulum Control System
}

\author{
Gai $\mathrm{Di}^{1, a}$, Ligang Chen ${ }^{1, b}$ \\ ${ }^{1}$ School of Mechanical and Electrical Engineering, Qingdao binhai University, Qingdao 266555, \\ China; \\ A1265834621@qq.com
}

Keywords: STM32 embedded system, gyroscope MPU 9150,PID algorithm.

\begin{abstract}
The whole system is composed of STM32 embedded system module, gyroscope MPU 9150 module, DC Blower module,trestle module,power module, LED and LCD display module, key mode selection module,alarm module.Wind pendulum control system is based on STM32 embedded system, using STM32 as control system,using the gyroscope MPU-9150 measured the real-time data,using the PID algorithm[1], real-time corrected the output PWM value for each DC blower,it corrected the parameter feedback real-time,reduced the system error (error about $\pm 2 \mathrm{~cm}$ )effectively.It swung in the range of $0^{\circ}$ to359 ${ }^{\circ}$, at the same time,LED hinted in different mode switching.key selection mode,then it alarmed when mission accomplished.In the process of actual operation, according to the requirement of the topic, the system has realized the function of fast swing, drawing line and circle and the rapid recovery of static in certain angle,In the experiment, the parameters are accurate[2].
\end{abstract}

\section{Design requirements}

Hardware design:Four DC blowers with carbon fiber tube are fixed on the trestle through gimbal.A laser pen is mounted at the center of bottom.As shown in Figure 1.Choose one direction as 0 degree, which is starting, clockwise turn to 90 degrees, 180 degrees, 270 degrees, etc.The DC blower is the only power to drive the system.After the task is completed, there is a sound or light alarm,easy to test record.

1.The system starts from a standstill,control wind pendulum to do similar free swing motion in $15 \mathrm{~s}$, the laser pen draws a length not less than $50 \mathrm{~cm}$ of the straight line segment in the ground,the deviation is not more than $\pm 2.5 \mathrm{~cm}$,and have good repeatability.

2.The system starts from a standstill,the system can complete the swing of the controllable amplitude in 15s,Draw a line between 30 and 60, The deviation is not more than $\pm 2.5 \mathrm{~cm}$,And have good repeatability.

3.wo can set the direction of swing,beginning the still,Swing in the direction in advance.The laser pen draws a length not less than $20 \mathrm{~cm}$ of the straight line segment in the ground.

4.Release the wind force to a certain angle (30 45 degrees), Make the wind pendulum to reach the rest in $5 \mathrm{~s}$.

5.Laser pen is driven to draw a circle on the ground,need to repeat 3 times in 30s.Radius can be set in the range of $15 \sim 35 \mathrm{~cm}$.

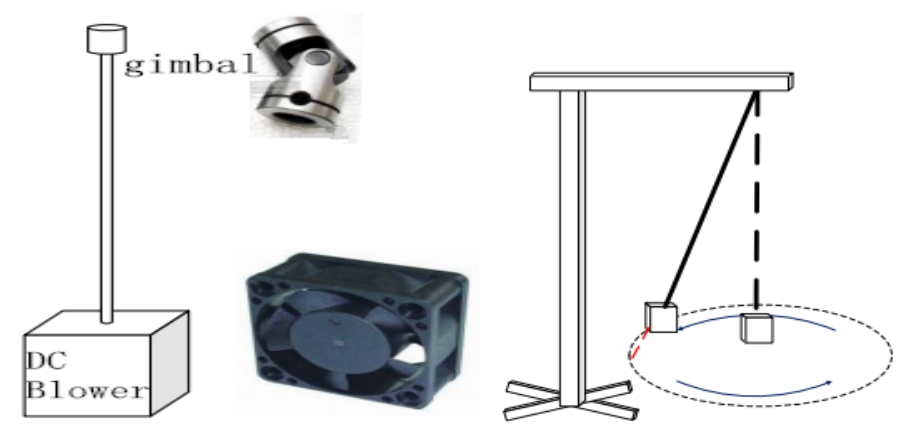

Fig 1 Wind pendulum implementation scheme

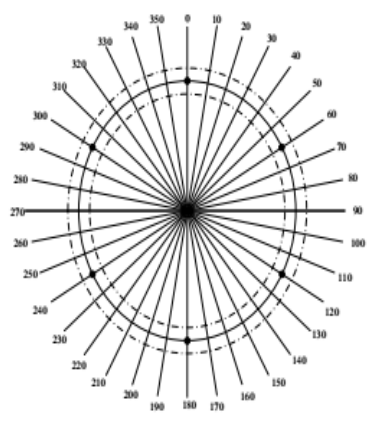

Fig 2 Test field 


\section{The overall design of system}

The overall block diagram. The wind pendulum system consists of STM32 control module, a gyroscope MPU-9150, a key module, a power supply module, a wind pendulum module, a sound and light alarm module, and a system trestle.Forming a closed loop control system,Controller processing feedback data with PID algorithm.Controller controls the air flow of four DC blower,continuously collects the current attitude angle of wind pendulum,so as to meet the design requirements[3].The overall block diagram of system as show in Fig 3.

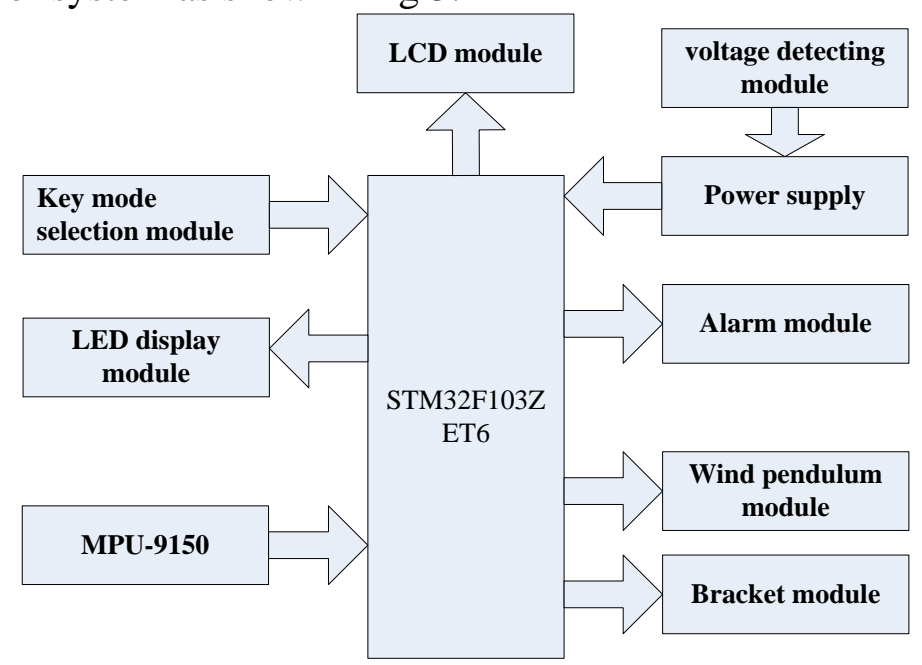

Fig 3. The overall block diagram of system

\section{Software design}

Using the key module as the system mode selection switch,System boot into the initialization interface,press the button to enter the menu selection interface[4].Menu selection interface has 6 functions:The system can choose to enter the corresponding function through the keys.System back to the menu selection interface after the execution of the function.Continue to wait for the next task[5].

The chart of system as show in Fig 4.

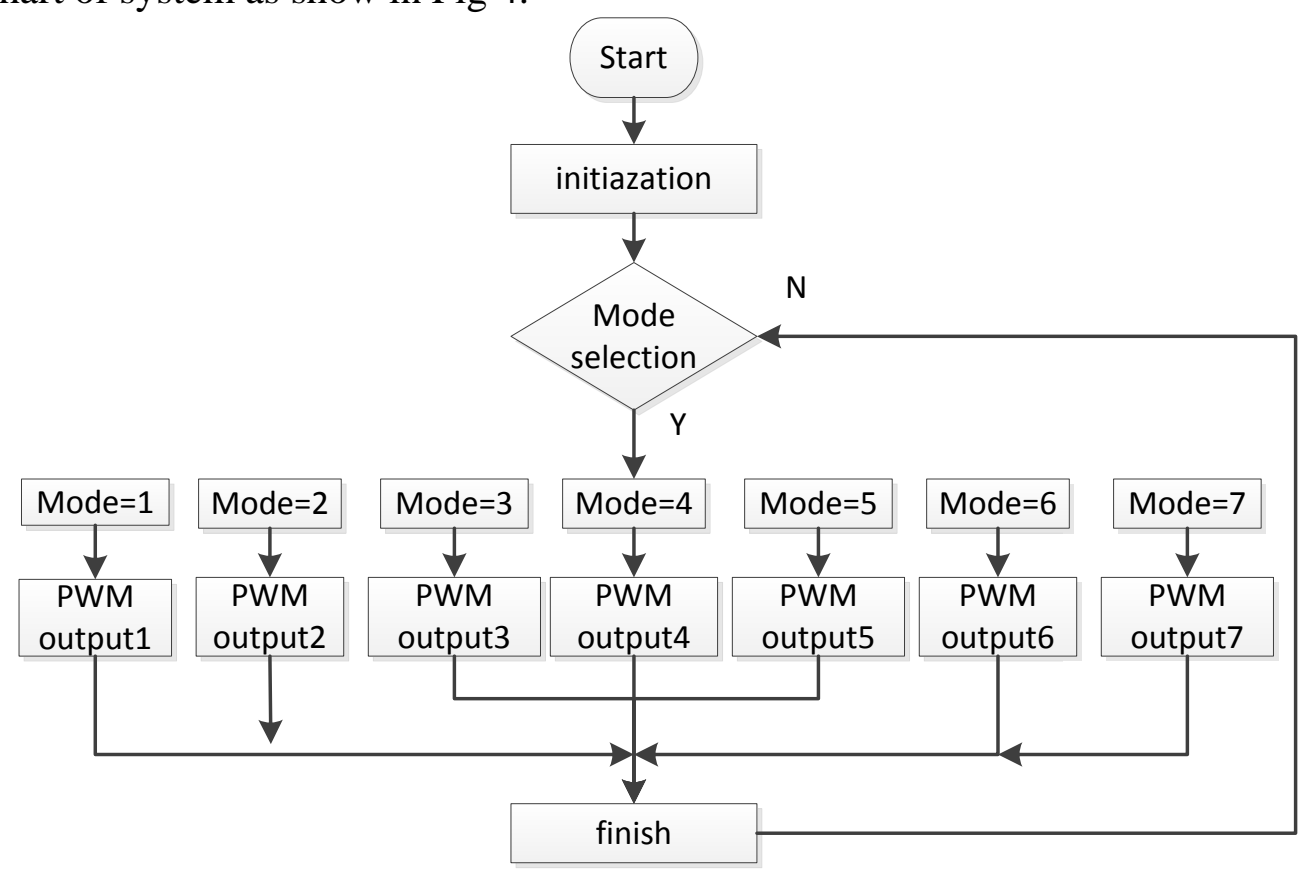

Fig 4.The chart of system 
System test

Test instrument

Chronograph, protractor, straightedge,electric fan,computer.

Test data

1.The laser pen draws a length not less than $50 \mathrm{~cm}$ of the straight line segment in the ground,repeat five times,record test data as shown in table 1

Table $150 \mathrm{~cm}$ Straight line test

\begin{tabular}{lllllll}
\hline & Time & Deviation & Deviation & Deviation & Deviation & Deviation \\
& $(\mathrm{s})$ & 1 & 2 & 3 & 4 & 5 \\
\cline { 1 - 5 } First test & 4.1 & 0.9 & 0.8 & 0.8 & 0.9 & 0.8 \\
Second test & 3.9 & 1.3 & 1.2 & 1.1 & 1.2 & 1.0 \\
Third test & 4.2 & 1.3 & 1.2 & 1.4 & 1.3 & 1.2 \\
\hline
\end{tabular}

2.Set draw line length,Drive wind pendulum swing,record time and deviation from rest to start free swing.

Table 2 different length linear test

\begin{tabular}{|c|c|c|c|c|c|c|}
\hline $\begin{array}{l}\text { Straight } \\
\text { line }\end{array}$ & $\begin{array}{l}\text { Time } \\
\text { (s) }\end{array}$ & $\begin{array}{l}\text { Deviation } \\
1\end{array}$ & $\begin{array}{l}\text { Deviation } \\
2\end{array}$ & $\begin{array}{l}\text { Deviation } \\
3\end{array}$ & $\begin{array}{l}\text { Deviation } \\
4\end{array}$ & $\begin{array}{l}\text { Deviation } \\
5\end{array}$ \\
\hline $30 \mathrm{~cm}$ & 2.7 & 2.2 & 1.9 & 2.1 & 2.2 & 2.1 \\
\hline $40 \mathrm{~cm}$ & 3.2 & 1.9 & 1.8 & 1.6 & 1.7 & 1.8 \\
\hline $50 \mathrm{~cm}$ & 4.1 & 1.3 & 1.2 & 1.0 & 1.1 & 0.9 \\
\hline $60 \mathrm{~cm}$ & 4.6 & 1.4 & 1.4 & 1.3 & 1.4 & 1.2 \\
\hline
\end{tabular}

3.Set swing angle,beginning,Record time from rest to start free,record deviation in different angle.

Table 3 different angle line test

\begin{tabular}{lllllll}
\hline $\begin{array}{l}\text { Different } \\
\text { Angle line }\end{array}$ & $\begin{array}{l}\text { Time } \\
\text { (s) }\end{array}$ & $\begin{array}{l}\text { Deviation } \\
1\end{array}$ & $\begin{array}{l}\text { Deviation } \\
\text { D Deviation }\end{array}$ & $\begin{array}{l}\text { Deviation } \\
\text { Deviation }\end{array}$ & 3 \\
\hline $0^{\circ}$ line & 3.0 & 1.0 & 1.1 & 1.1 & 1.2 & 1.2 \\
$90^{\circ}$ line & 3.4 & 1.2 & 1.2 & 1.3 & 1.2 & 1.3 \\
$180^{\circ}$ line & 3.6 & 1.4 & 1.3 & 1.4 & 1.3 & 1.3 \\
$270^{\circ}$ line & 3.8 & 1.5 & 1.7 & 1.6 & 1.7 & 1.5 \\
$360^{\circ}$ line & 3.1 & 1.8 & 1.7 & 1.6 & 1.5 & 1.5 \\
\hline
\end{tabular}

4.Pull the wind pendulum up and let it go,Drive the blower to start work,Test time that the wind pendulum to reach the standstill.

Table 4 test the time to reach the standstill

\begin{tabular}{llllll}
\hline lift & Time 1 & Time 2 & Time3 & Time 4 & Time 5 \\
\cline { 1 - 5 } $30^{\circ}$ & 2.3 & 2.4 & 2.4 & 2.3 & 2.2 \\
$35^{\circ}$ & 3.0 & 3.2 & 3.9 & 3.3 & 3.1 \\
$40^{\circ}$ & 4.2 & 4.1 & 4.1 & 4.0 & 3.9 \\
$45^{\circ}$ & 4.3 & 4.2 & 4.2 & 4.3 & 4.2 \\
\hline
\end{tabular}

\section{Summary}

The most difficult part of the wind pendulum test system is angle's control.In order to make the system achieve the shortest time to reach the standstill,control as required,In the design and testing, the four DC blowers are used as the driving force,during debugging,in order to reduce the deviation,to swing the system in a specified range,using STM32 as a controller,combined PID algorithm,fully meet the design requirements,in order to reduce resistance,the system is fixed by the light material.After tested,the wind pendulum system meets the design requirements[6].All kinds of test parameters are accurate and reliable. 


\section{References}

[1] Astr6m K J and Hligglund T.Automatic tuning of PID controllers, Research Triangel Park,North Carolina:Instrument Society of America,1998.

[2] Astr6m K J and Hligglund T.PID controllers,2nd Edition,Research Triangel Park,North Carolina:Instrument Society of America,1995.

[3] Voda A A and Landau L D.A method for the auto-calibratioa of PID controllers.Automatic,1995,31(1):41-53.

[4] Gawthrop P J and Nomikos P E. Automatic tuning of commercial PID controllers for single-loop and multiloop applications. IEEE Control Syst.Mag,1998,10:34-42.

[5] Astrom $\mathrm{K}$ J,Hang $\mathrm{C}$ C,Persson p,and Ho $\mathrm{w}$ k.Towards intelligent PID control.Automatica,1992,28,28(1)1-9.

[6] Persson P and Astrom K J PID control revisited.In Preprints IFAC 12th World Congress,Sydney,Australia,1993. 